\title{
INCENTIVE SPIROMETRY: ITS VALUE AFTER CARDIAC SURGERY
}

\author{
G.D. GALE AND D. E. SANDERS
}

A BSTRaCt

\begin{abstract}
Treatment with intermittent positive pressure breathing (IPPB) and incentive spirometry (I.S.) was compared in 109 patients after heart surgery with cardiopulmonary bypass. Assessment was done by measurement of vital capacity, arterial oxygen tension and identification of the radiological signs of atelectasis. All patients were instructed pre-operatively in the treatment which was to be used.

Vital capacity, arterial oxygen tension while breathing air for the first three postoperative days and the incidence of atelectasis showed no significant difference between groups. Ten minutes after treatment the arterial oxygen tension fell, but this was only statistically significant after I.P.P.B. At 60 minutes the arterial oxygen tension had returned to pretreatment level in both groups.

The use of the incentive spirometer four times daily is no better than I.P.P.B. in preventing atelectasis after open-heart surgery. Possibly incentive spirometer treatment given more frequently may be more effective.
\end{abstract}

THE INCIDENCE OF ATELECTASIS after heart operations with cardiopulmonary bypass is still $60-84$ per cent in spite of careful fluid and respiratory management during and after operation. 'A reduction in pulmonary complications by the use of the incentive spirometer (I.S.) has been shown after laparotomy, ${ }^{2}$ adrenalectomy ${ }^{3}$ and cardiac surgery. ${ }^{4} \mathrm{An}$ assessment of the BartlettEdwards incentive spirometer in this hospital in 34 patients after cardiac surgery failed to show a reduction in the rate of atelectasis. ${ }^{5}$ These results suggested that a further study was required to determine the value of incentive spirometry, which would best be done by comparing it to intermittent positive pressure breathing (I.P.P.B.) because that form of treatment has been found to be ineffective, ${ }^{4,6}$ although this view has been questioned.? Patient consent was not considered necessary because both forms of treatment were already in use in 1974. The protocol underwent peer review by the anaesthetic research committee of Toronto General Hospital, which complied with local hospital regulations regarding clinical studies at that time. Both treatments were to be given four times a day because that has been the usual schedule for I.P.P.B. in the past and is not so frequent that it will tire patients.

G.D. Gale, M.B., B.Ch., F.F.A.R.C.S., F.R.C.P. (C), Department of Anaesthesia; D.E. Sanders, M.D. F.R.C.P. (C), Department of Radiology. University of Toronto, Toronto General Hospital, 101 College Street, Toronto, Ontario, MSG IL7.

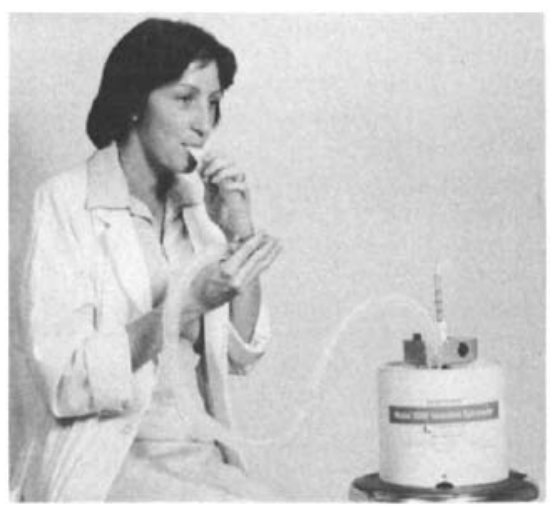

Figure 1 The Bartlett-Edwards model 3000 incentive spirometer. Note the Reuben valve in the subject's right hand so that she can inhale from the spirometer and then exhale to atmosphere without removing the mouthpiece.

\section{METHOD}

The incentive spirometer (Figure I)

The Bartlett-Edwards Incentive Spirometer consists of a cylinder and piston with an adjustable volume of 200 to $2,500 \mathrm{ml}$. On top of the cylinder there is a volume indicator, a batteryoperated light bulb and an incidence counter. An airway hose leads from the top of the cylinder to a mouthpiece. The patient inhales through the mouthpiece and draws air from the cylinder, causing the piston to rise. When the predetermined volume is reached the incidence 


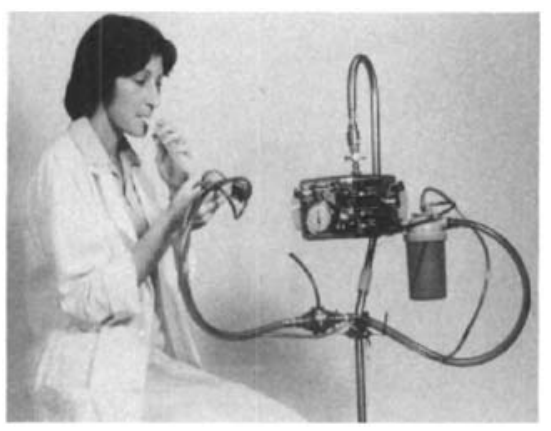

FIGURE 2 I.P.P.B. using a Bird mark 7 ventilator.

counter is tripped and a switch is closed, turning on the light. There is a small constant leak in the spirometer so that the patient must continue to inhale to keep the light on. When inspiratory flow ceases, the piston falls and the light goes out. Sitting as nearly upright as possible the patient is asked to breathe out into the room and then to take a big breath from the mouthpiece, so that the light goes on. He then keeps the light on as long as possible by breathing in and then exhales slowly. The light provides the patient with a visual reward for reaching the pre-set inspiratory volume. Enough time should be allowed between breaths to prevent patient fatigue, with a minimum of ten deep breaths in a treatment time of 20 minutes. Both I.S. and I.P.P.B. treatments are administered by the respiratory therapist on call in the intensive care unit.

Intermittent positive pressure breathing (Figure 2)

A Bird ventilator with a mouthpiece was used with pressure and flow at the discretion of the Respiratory Technologist, usually achieving twenty breaths in the course of one treatment, over $\mathbf{2 0}$ minutes. Inspiratory pressure was usually set at 20 centimeters of water at 15 litres per minute initially, and then adjusted according to the patient's lung compliance.

\section{Treatment schedule}

Pre-operatively the patients were instructed in the chosen method of therapy. Post-operative treatment was begun two hours after tracheal extubation on a schedule with four treatments bet ween 0900 and 2200 hours. The first treatment usually took place between 1000 and 1200 hours with the second treatment four hours later. The treatment schedule lasted three days, or longer if abnormal signs were present in the chest or on the chest X-ray. Postoperative analgesia and seda- tion were provided with small doses of morphine $(2-4 \mathrm{mg})$ and diazepam $(2.5 \mathrm{mg})$ given intravenously as required.

\section{The assessment of therapy}

The effect of treatment was assessed by clinical examination of the chest. looking for poor basal air entry, râles and rhonchi, and by changes in the vital capacity and arterial oxygenation. Atelectasis was diagnosed radiologically

1. Vital capacity was measured using a vitalograph before and after training with I.S. or I.P.P.B., and then just before and after the first two postoperative treatments.

2. Arterial blood gases were measured just before and 10 and 60 minutes after the first two postoperative treatments, with a constant inspired oxygen fraction using a Wexler mask, with the patient in the recumbent position. The inspired oxygen fraction was chosen to provide a radial artery oxygen tension of $11-16 \mathrm{kPa}(80-120$ $\mathrm{mm} \mathrm{Hg}$ ). The inspired oxygen fraction was kept the same 101060 minutes after treatment. In most cases the inspired fraction was 0.4 but in a few cases it was higher.

3. Arterial blood gases were measured at least one hour after the last treatment of physiotherapy after breathing air for five minutes on the afternoon of the first, and the morning of the second and third postoperative days.

4. Chest X-rays, P.A. and lateral preoperatively and then films early after operation, at 24 and 48 hours and every two days thereafter unless required more frequently. A short time-exposure of one-twentieth of a second or less was used with a high kilovoltage technique to ensure good films. After tracheal extubation films were taken in the upright position with additional lateral views.

\section{Atelectasis}

In this study, atelectasis was classified on radiological evidence as plate, subsegmental, segmental or lobar in type. Plate atelectasis (synonymous with disk atelectasis) is described by Fraser and Paré. ${ }^{9}$ It consists of linear densities almost always at the lung bases, roughly horizontal or slightly oblique, varying in thickness from one to three millimeters and commonly several centimeters in length. Lines due to plate atelectasis invariably extend to a pleural surface.

\section{Patient population}

One hundred and nine patients consecutively anaesthetized by one of the authors for heart surgery with cardiopulmonary bypass were allo- 
TABLE I

The Operations Performed in the Two TREATMENT GROUPS

\begin{tabular}{lrc}
\hline \hline & \multicolumn{2}{c}{ Number of patients } \\
\cline { 2 - 3 } & I.S. & I.P.P.B. \\
\hline Multiple valve replacement & 2 & 2 \\
Mitral valve replacement & 7 & 5 \\
Mitral split & 0 & 2 \\
Aortic valve replacement & 7 & 7 \\
Aorto coronary bypass & 33 & 41 \\
Septal defects & 3 & 1 \\
Left atrial myxoma & 1 & 0 \\
Intra-aortic balloon & 2 & 3 \\
Re-opened for bleeding & 2 & 0 \\
Total & 52 & 57 \\
\hline
\end{tabular}

In each group, one aortic valve had a single aortocoronary bypass. In the multiple valve category, the I.S. and I.P.P.B. patients received five and four valves respectively.

cated randomly to one of the two groups for treatment with I.S. or I.P.P.B.

Analysis of age, height, weight. cardiac catheterization data, smoking habits, presence of productive cough preoperatively, cardiopulmonary bypass time, positive fluid balance at the end of cardiopulmonary bypass, length of postoperative ventilation and blood loss in the first 24 hours after operation showed no difference between the two groups when compared using Student's t-test on arithmetic averages and geometric means calculated from the logarithmic transformation of the observations. The operations done are shown in Table I. The mean number of aorto-coronary bypass grafts was 2.12 for I.S. and 1.98 for I.P.P.B.

Statistical assessment of the arterial oxygen tension and results of vital capacity was done by Student's t-test, paired for those measurements obtained on the same patient, unpaired otherwise. The analyses were done following a logarithmic transformation of the data which stabilized their variance and yielded geometric means. The effects of the first and second treatment periods were compared by analysis of variance allowing for repeated measurements in subjects of the two groups. The radiological findings were evaluated by simple contingency table analysis.

\section{Results}

Vital capacity (Figure 3)

Vital capacity rose by 3.5 and 4.5 per cent respectively after Iraining with I.S. and I P.P.B. Neither change was significant.

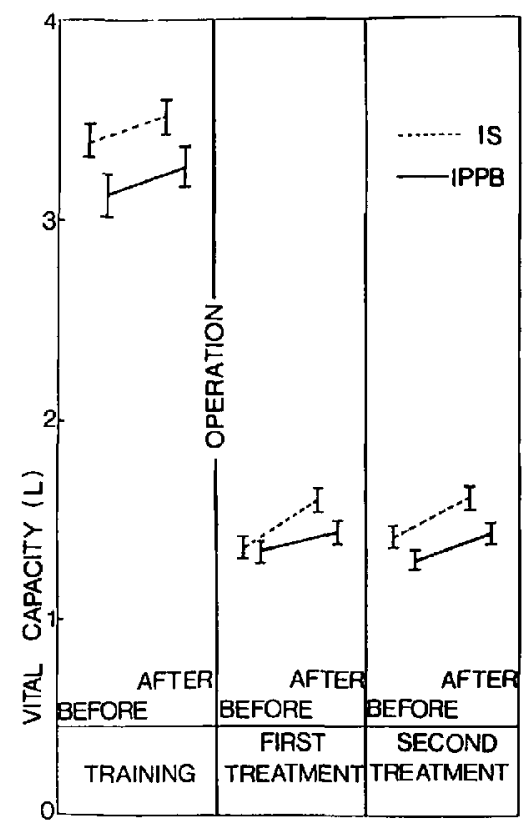

FIGURE 3 Arithmetric mean of vital capacity measured before and after training and the first two postoperative treatments with the Bartlett-Edwards Incentive Spirometer (I.S.) and intermittent positive pressure breathing (I.P.P.B.).

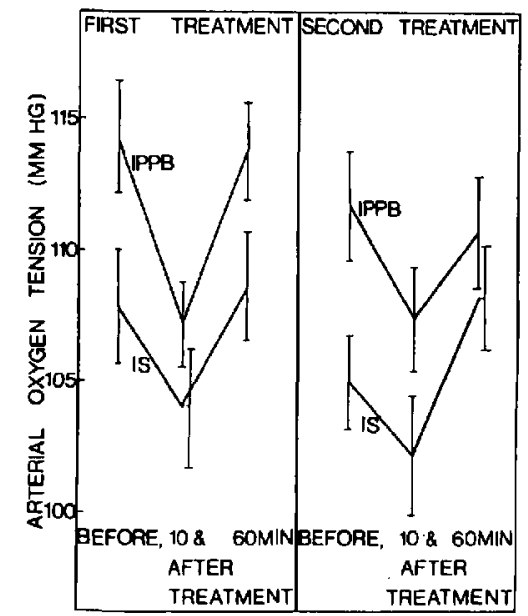

FIGURE 4 Geometric mean of arterial oxygen tension before treatment, 10 and 60 minutes after treatment with intermittent positive pressure breathing (I.P.P.B.) and the incentive spirometer (I.S.). The fall in oxygen tension ten minutes after treatment is significant after I.P.P.B. $(p<0.01)$ but not after I.S. 
TABLE II

arterial Oxygen Tension

\begin{tabular}{lccc}
\hline \multicolumn{1}{c}{ Day } & 1 & 2 & 3 \\
\hline I.S. & $59.3 \pm 1.8$ & $59.2 \pm 1.7$ & $60.6 \pm 1.9$ \\
I.P.P.B. & $62.6 \pm 1.6$ & $57.1 \pm 1.8$ & $59.4 \pm 1.6$ \\
\hline
\end{tabular}

This shows the arithmetrical mean and the standard crror of oxygen lensions after breathing air for five minutes on the first three days after operation with no significant difference between the two groups.

After operation, vital capacity in I.S. and I.P.P.B. groups fell significantly $(p<0.001)$ to 43 and 45 per cent respectively of the preoperative vital capacity. Vital capacity always increased after postoperative treatment, 17.5 per cent $(p<$ $0.001)$ and 14.3 per cent $(p<0.001)$ after the first and second I.S. treatment and 7.4 per cent $(p<$ 0.05 ) and 10.7 per cent $(p<0.01)$ respectively after the two I.P.P.B. treatments. Only during the first treatment period was the increase significantly higher $(p<0.05)$ following I.S, than after I.P.P.B. treatment.

\section{Arterial oxygen tension (Figure 4)}

Ten minutes after the first and second I.S. treatments the mean arterial oxygen tension decreased by 3.6 and 2.8 per cent respectively, which was not a significant change. Ten minutes after the first and second I.P.P.B. treatments, the oxygen tension decreased significantly by 6.1 and 6.4 per cent respectively $(p<0.01)$. Sixty minutes after I.S. or I.P.P.B. treatment, the oxygen tension was not significantly different from pretreatment values.

The mean arterial oxygen tension after breath. ing air for five minutes was about $8 \mathrm{kPa}(60 \mathrm{~mm}$ $\mathrm{Hg})$ in both groups during the first three postoperative days (Table II).

The radiological survey (Table III)

There was no difference in radiological evidence of respiratory complications in the two groups. The incidence of atelectasis in I.S. and I.P.P.B. groups was respectively; any kind of atelectasis 65 and 70 per cent; plate alone 51 and 53 per cent.

Plate atelectasis was over three times as frequent as subsegmental atelectasis. The distribution of atelectasis in the lungs was the same in both groups with four times as much in the basal as in the middle zones. Apical atelectasis occurred only three times. The frequency of atelectasis was the same in each lung in both groups.

\section{Discussion}

Results of this study show that after heart surgery, treatment with I.S. was not significantly better than I.P.P.B. in preventing atelectasis. The rate of atelectasis was the same in both groups, and similar to a group of patients who had neither of these treatments. ${ }^{2}$ The same result was found in a study ${ }^{10}$ in which I.P.P.B. two-hourly, was compared with hourly incentive spirometry using the "Inspirex", which is cylinder and ball type spirometer made by the Inspiron Company. Other studies have found the I.S. treatment to be effective when using the "Spirocare" hourly" and two hourly ${ }^{12}$.

Just before the first postoperative treatment the average vital capacity of both groups fell to 44 per cent of the preoperative value (Figure 3 ). The extremes of this change occurred in patients with a small vital capacity who had triple and aortic valve replacements respectively. Since most patients cope with this it demonstrates that they normally have a large respiratory reserve, but associated with its reduction after heart operations there is a high rate of atelectasis and hypoxaemia. In comparison, a lesser degree of respiratory impairment occurred after abdominal surgery when postoperative vital capacity fell to 60 per cent of the preoperative vital capacity, ${ }^{2}$ while another study ${ }^{13}$ found it to be only 45 per cent of predicted value.

TABLE III

INCIDENCE OF RESPIRATORY COMPLICATIONS

\begin{tabular}{lccccccccc}
\hline \hline & & \multicolumn{9}{c}{ Atelectasis } & & & \\
\cline { 2 - 9 } & $\begin{array}{l}\text { Total } \\
\text { cases }\end{array}$ & $\begin{array}{c}\text { Any } \\
\text { kind }\end{array}$ & Plate & Subsegmental & Segmental & Lobar & Effusions & $\begin{array}{c}\text { Heart } \\
\text { failure }\end{array}$ \\
\hline I.S. & 51 & 33 & 26 & 8 & 2 & 1 & 27 & 8 \\
I.P.P.B. & 57 & 40 & 30 & 9 & 7 & 0 & 36 & 6 \\
\hline
\end{tabular}

Plate atelectusis and small effusions are the commonest. 
TABLE IV

Distribution OF ATELECTASIS

\begin{tabular}{lcccccc}
\hline \hline & Upper & Mid & Basal & $\begin{array}{l}\text { Right } \\
\text { Only }\end{array}$ & $\begin{array}{r}\text { Left } \\
\text { Only }\end{array}$ & Bilateral \\
\hline I.S. & 2 & 7 & 28 & 10 & 6 & 19 \\
I.P.P.B. & 1 & 8 & 33 & 14 & 14 & 19 \\
\hline
\end{tabular}

The distribution of atelectasis in 51 I.S. and 57 I.P.P.B. cases.

Clinical observation suggests that pain restricts vital capacity after thoracotomy. Sharp chest pain on inspiration may be due to pleuritic or pericardial friction while the chest drains cause pain at their epigastric insertion site. For a week or more, pain over the sternum may occur on coughing, which appears to be due to tension in the sternal wires. Intravenous morphine was used early for pain relief but perhaps analgesic concentrations of nitrous oxide might provide more analgesia without respiratory depression. ${ }^{14}$

Fatigue appears to be a factor in the decline of respiratory elfort that occurs in the first postoperative day, whilst emotional depression is often apparent two or three days later. Since the use of maximal inspiration with I.S. is a voluntary activity, the patient's state of mind may well influence the effectiveness of the incentive in terms of volume inspired, the duration that full inspiration is held, and the frequency of goals achieved or attempted. If the depressed patient declines to perform, then obviously the treatment will be ineffective. Many other factors will reduce vital capacity including anaesthetic drugs, anxiety, fear of breathing deeply, interstitial pulmonary oedema, mucus in the airways, increased airway resistance and decreased compliance after cardiopulmonary bypass, abdominal distention, ' supine position and immobilization.

There was a trend to hypoxaemia in both groups after each treatment but this was only significant after I.P.P.B. This may be due to increased oxygen consumption during deep breathing with the I.S. but this explanation is not applicable to I.P.P.B. because of its passive nature. The hypoxaemia effect of I.P.P.B. has been described before ${ }^{16}$ and may be due to ventilation/perfusion mismatch due to passive overventilation of apical alveoli at the expense of basal alveoli, which receive less ventilation because lung compliance is lower at the bases at low lung volume. ${ }^{17}$ This would increase the proportion of venous admixture due to shunted blood from the poorly ventilated lung bases.

Pressure effects of I.P.P.B. in the chest may reduce cardiac output and oxygen delivery to the tissues. This would not apply to I.S. treatment. which would tend to improve venous return. Like physiotherapy both 1.S. and I.P.P.B. may have an effect to mobilize bronchial secretions, causing a temporary fall in the ventilation/perfusion ratio with increased shunting and hypoxaemia.

Earlier studies have shown a gradual decline of arterial oxygen tension on the first postoperative day. ${ }^{18}$ This effect will oppose any trend of arterial oxygen tension to rise after treatment in the early postoperative period. Bartlett ${ }^{2}$ found that the oxygen tension rose post-operatively in laparotomy patients when yawning manoeuvres were repeated. A significant rise in arterial oxygen tension may occur after more frequent I.S. treatment.

\section{Conclusion}

The use of the Bartlelt-Edwards incentive spirometer four times a day is no better than I.P.P.B. in the prevention of atelectasis in patients after open-heart surgery. Possibly more frequent treatment might be effective.

\section{REFERENCES}

1. Gale, G.D. Teasdale, S.J. Sanders, D E Bradwell, P.J., Russell, A., Solaric, B. \& YORK, J.E. Pulmonary atelectasis and other respiratory complications after cardiopulmonary bypass and investigation of aetiological factors. Canad. Anaesth. Soc. J. 26: 15 (1979).

2. Bartlett, R.H., Brennan, M.L., Gazzaniga, A.B. \& Hanson, E.L. Studies on the pathogenesis and prevention of post-operative pulmonary complications. Surg. Gynaecol. Obstet. 137: 925 (1973).

3. VAN DE WATER, J.M., WATRING, W.G., LINTON, L.A., MurPhy, M. \& BYron, R.L. Prevention of post-operative pulmonary complications. Surg. Gynaecol. Obstet. 135: 229 (1972).

4. IVERSON, L.I.G., ECKER, R.R., Fox, H.E.\& MAY, I. A. A compartive study of IPPB, the incentive spirometer and blow bottles; the prevention of atelectasis following cardiac surgery. Ann. of Thorac. Surg. 25: 197 (1978).

5. GALE, G.D \& SANDERS, D.E. The BartlettEdwards incentive spirometer; a preliminary assessment of its use in the prevention of stelectasis 
after cardio-pulmonary bypass. Canad. Anaesth. Soc. J. 24: 408 (1977)

6. McConnell, D.H., Maloney, J.V. \& BuckBERG, G.D. Post-operative intermittent positive pressure breathing treatments. J. Thoracic Cardiovasc. Surg. 68: 944 (1974).

7. Noehren, T.H. \& Klauber, M.R. Controversy of intermittent positive pressure breathing. Chest 73: $782(1978)$

8. Wexler, H.R., Aberman, A., Scott, A.A. \& COOPER, J.D. Measurement of intratracheal oxygen concentrations during face mask administration of oxygen. A modification for improved control. Canad. Anaesth. Soc. J. 22:416(1975).

9. Fraser, R.G. \& Paré, J.A. Diagnosis of diseases of the chest. Vol. I, 301. W.B.Saunders Company, Toronto $(1970)$

10. Ghattas, M.A., Salinger, S., Cosgrove, D. \& Estafanos, F. Pulmonary functions after openheart surgery, cffect and cost of intermittent position pressure breathing (I.P.P.B.) and incentive spirometry. Crit. Care Medicine 7: 141 (1979).

11. Prins, L.S. An evaluation of incentive breathing as a prevention of atelectasia in open-heart patients. Respiratory Technology 14: 2,9 (Summer 1978).

12. Freid, J.L. An evaluation of therapy to prevent post-operative atelectasis. Respiratory Therapy 7: 3, 55 (May/June, 1977).

13. Brooks, J.A. A comparison of voluntary deep breathing with inspiratory hold and the deep breathing exercises on increasing lung volumes in post-operative upper abdominal surgical patients (In press).

4. Parbrook, G.D. Therapeutic uses of nitrous oxide. A review. Brit. J. Anaesth. 40:365 (1968).

15. ANDERSON N.B. \& GHIA, J. Pulmonary function, cardiac status and post-operative course in relation to cardiopulmonary bypass. J. Thorac. and Cardiovasc. Surg. 59: 474 (1970).

16. Wright, F.G., Foley, M.F., Downs, J.B. \& HodGes, M.R. Hypoxemia and hypocarbia following intermittent positive pressure breathing. Anaesthesia and Analgesia, Current Researches 55: 555 (1976).

17. West, J.B. Ventilation, blood flow and gas exchange. Second Ed. Oxford. Blackwell Scientific Publications. Inequality of blood flow and ventilation in the normal lung p. 31 (1970).

18 Turnbull, K.W., Miyagishima, R.T. \& GeREIN, A.N. Pulmonary complications and cardiopulmonary bypass: a clinical study in adults. Canad. Anaesth. Soc. J. 21:181 (1974).

RÉSUMÉ

On a comparé la spirométrie incitative aux traitements avec pression positive intermittente en phase post-opératoire chez 109 opérés à cour ouvert. Les paramètres mesurés et comparés étaient la capacité vitale, la $\mathrm{Pa}_{\mathrm{O}_{2}}$ et les signes radiologiques d'adélectasie. L'une ou l'autre méthode, selon le cas, était enreingée aux malades avant la chirurgie

Les capacités vitales et les $\mathrm{Pa}_{\mathrm{O}_{2}}$ en respiration à l'air ambiant, au cours des trois premiers jours après chirurgie, ainsi que ['incidence d'atélectasie n'étaient pas différents de façon significative entre les patients des deux groupes. $\mathrm{La} \mathrm{Pa}_{\mathrm{O}_{2}}$ s’abaissait 10 minutes après les traitements mais cette baisse n'était significative que dans le groupe traité avec la pression positive intermittente. Une heure après les traitements, ces $\mathrm{Pa}_{\mathrm{O}_{2}}$ étaient comparables aux valeurs avant traitement. L'utilisation de spirométrie incitative quatre fois par jour n'est pas supérieure aux traitements avec pression positive intermittente comme méthode de prévention de l'atélectasie pulmonaire après chirurgie cardiaque. Peut-être la spirométrie incitative utilisée plus de quatre fois par jour serait-elle plus efficace. 